\title{
Do prescrito ao real: a gestão individual e coletiva dos trabalhadores de enfermagem frente ao risco de acidente de trabalho
}

\section{From prescribed to real: the collective and individual management of nursing workers toward the risk of workplace accidents}

\author{
Davidson Passos Mendes ${ }^{1}$ \\ Mariana Muniz de Oliveira ${ }^{2}$ \\ Virgínia Gonçalves de Matos ${ }^{2}$ \\ Marcela Borja Mazoni \\ Geraldo Fabiano de Souza Moraes ${ }^{1}$
}

\begin{abstract}
Resumo: Esse artigo tem por objetivo levantar os constrangimentos enfrentados pelos auxiliares e técnicos de enfermagem (AeTE) de uma instituição pediátrica, vinculada a uma fundação estatal, em sua atividade de trabalho e identificar estratégias utilizadas por eles que garantam as metas de produção, a satisfação do trabalhador e a sua autoproteção contra os acidentes de trabalho. Por meio do método da AET, foram utilizados para análise e coleta de dados 34 trabalhadores de enfermagem - nível médio e técnico -, entre efetivos e contratados e, observadas as estratégias de ação e regulação destes trabalhadores frente às interfaces com que lidam. Os resultados mostram que entre os constrangimentos levantados nesta Instituição, os mais evidentes são: a dupla jornada de trabalho, a diversidade de vínculos empregatícios, os riscos a que estes profissionais estão expostos e o não conhecimento do objeto de trabalho. Verifica-se que esses constrangimentos ocasionam uma elevação das cargas de trabalho física, psíquica e cognitiva. Visando reduzir essas cargas de trabalho, o trabalhador tenta criar estratégias que são adquiridas por meio da vivência com o trabalho, das experiências e valores, para se regular frente ao risco no trabalho.
\end{abstract}

Palavras-chave: Saúde do trabalhador. Ergonomia. Enfermagem. Carga de trabalho.

\begin{abstract}
The objective of this study is to analyze the constraints faced by the nursing assistants and technicians in a pediatric clinic sponsored by a state foundation during their work activities and identify the strategies adopted by them in order to guarantee the achievement of their production goals and job satisfaction and ensure their protection against workplace accidents. The method of Ergonomic Work Analysis (EWA) was used for analysis and data collection of 59 tenured and temporary nursing workers with intermediate and technical level of education and to investigate the strategies related to actions and employment regulation concerning the interfaces they deal with. The results show that among the constraints assessed in this institution the most evident are: double shift, diversity of employment contracts (tenure and temporary), risks to which these professionals are exposed, and the lack of knowledge about their object of work. It can be said that these constraints increase physical, psychic, and cognitive workload. Aiming to reduce such workloads, the workers try to develop strategies from their own experience, expertise, and values in order to deal with the risks in the workplace.
\end{abstract}

Keywords: Worker health. Ergonomics. Nursing. Workload.

\section{Introdução}

Em meados do século XIX, durante o período de Revolução Industrial, surge na Inglaterra a necessidade da criação do serviço de medicina do trabalho. Tal fato ocorreu devido ao aumento do consumo da força de trabalho e das precárias condições oferecidas aos trabalhadores (MENDES; DIAS, 1991).
O serviço de medicina do trabalho era constituído por um médico, que tinha como principal função promover o bem-estar físico e mental dos trabalhadores em seu local de trabalho. Com o passar do tempo, verificou-se o aumento dos agravos à saúde da população trabalhadora, gerando onerosos gastos

\footnotetext{
Curso de Engenharia de Saúde e Segurança, Universidade Federal de Itajubá - UNIFEI, Campus Itabira, Rua São Paulo, 377, ITEC, Bairro Amazonas, CEP 35900-373, Itabira, MG, Brasil, e-mail: davidson_mendes@yahoo.com.br; geraldofsmoraes@gmail.com

${ }^{2}$ Curso de Fisioterapia, Faculdade de Ciências Biológicas e da Saúde - FACIBIS, Centro Universitário Newton Paiva, Av. Silva Lobo, 1730, Nova Granada, CEP 30190-052, Belo Horizonte, MG, Brasil, e-mail: mmuniz_oliveira@yahoo.com.br; vgmatos@hotmail.com; marcelamazoni@yahoo.com.br
} 
diretos e indiretos ao empregador, além da insatisfação dos trabalhadores quanto à situação. Com isso, surgiu a necessidade de ampliar a atuação médica, substituindo o foco de uma visão centrada no indivíduo para uma visão interdisciplinar, a "Saúde Ocupacional" (MENDES; DIAS, 1991).

A insuficiência do modelo da Saúde Ocupacional favoreceu o surgimento da Saúde do Trabalhador, definida como processo de saúde e doença dos grupos humanos, em sua relação com o trabalho, com o objetivo de reduzir os índices de acidente de trabalho (MENDES; DIAS, 1991).

De acordo com o artigo 19 da lei 8.213, publicada em 24 de julho de 1991, acidente de trabalho é

[...] o que ocorre pelo exercício do trabalho a serviço da empresa, ou pelo exercício do trabalho do segurado especial, provocando lesão corporal ou perturbação funcional, de caráter temporário ou permanente [...] (PIZA, 1997, p. 7 apud EGGERS; GOEBEL, 2005).

Os acidentes de trabalho são classificados como típico, trajeto e adoecimento. Acidente típico é o acidente decorrente da característica da atividade profissional desempenhada pelo acidentado; $\mathrm{o}$ acidente de trajeto é o acidente ocorrido no trajeto entre a residência e o local de trabalho do segurado, e vice-versa, assim como nos horários de refeição. $\mathrm{O}$ adoecimento é entendido por doença do trabalho adquirida ou desencadeada em função das condições de trabalho (MENDES, 2003).

De acordo com a literatura, a incidência de acidentes de trabalho no Brasil vem sofrendo um acentuado declínio. O principal fator que justifica tal ocorrência seria a sonegação da notificação por parte das empresas. No entanto, estudos demonstram que este declínio também está associado a outros fatores distintos, porém complementares, tais como a reestruturação produtiva, modificações setoriais, desregulamentação dos direitos trabalhistas e flexibilização das relações de trabalho (WÜNSCH FILHO, 1999).

A reestruturação produtiva é caracterizada pela incorporação da informática e da robótica pela indústria, ocasionando taxas de desemprego ascendentes. Já as modificações setoriais são referentes ao deslocamento de trabalho do setor secundário para o terciário. A desregulamentação é marcada pela abolição dos direitos trabalhistas, desencadeando a informalização nas relações de trabalho (WÜNSCH FILHO, 1999).

Segundo Wünsch Filho, (1999, p. 46), “A estrutura de empregos no país modifica-se, com a eliminação de postos de trabalho na indústria e a ampliação do mercado de trabalho no setor de serviços".

A Ergonomia tem sido difundida como uma das mais importantes estratégias para reduzir os problemas originados por situações de trabalho, adaptando o ambiente de trabalho às necessidades do indivíduo, visando à preservação da saúde e o conforto dos trabalhadores (ALEXANDRE, 1998).

Enquanto ciência, a Ergonomia visa reconhecer na atividade a distância entre o prescrito e o real. O trabalho prescrito busca estabelecer a maneira como o trabalho deve ser executado, o tempo previsto para as operações, os modos operatórios e as regras por respeitar. Já o trabalho real é constituído pela atividade dos trabalhadores e sintetiza e integra os diferentes fatores que estruturam o processo de trabalho (FERREIRA; FREIRE, 2001). A atividade humana de trabalho configura singularmente cada situação de trabalho (ECHTERNACHT, 2008).

É na situação real de trabalho que a atividade permite identificar os determinantes que condicionam a sua interação com o meio. O processo incessante de construção de estratégias e modos operatórios pelo sujeito, para responder às exigências do trabalho, é o que distancia as noções entre o trabalho prescrito e o real (FERREIRA; FREIRE, 2001; MENDES; MORAES; MENDES, 2011).

Diferente de outras instituições, os hospitais são marcados pela complexidade e peculiaridade dos serviços prestados pelos trabalhadores de enfermagem. Esta peculiaridade afeta diretamente a moral das equipes de trabalho, que pode ser verificada nos baixos níveis de satisfação e motivação dos empregados e nos elevados níveis de absenteísmo e rotatividade (FERNANDES et al., 2002; REIS et al., 2003).

As atividades executadas pelos AeTE apresentam situações que exigem tomadas de decisões e organização de tarefas, originando cargas e exposição a riscos, os quais podem ser reduzidos por meio de adequado preparo profissional (FERNANDES et al., 2002; MENDES; MORAES; MENDES, 2011).

Entre os fatores de riscos do trabalho da enfermagem nos hospitais evidenciam-se: físicos (inadequação de iluminação, temperatura e ruídos); químicos (medicamentos, desinfetantes esterilizantes e gases anestésicos); biológicos (vírus, bactérias, fungos); psíquico (excesso de trabalho, relacionamento humano difícil); social (agressões físicas e/ou verbais) e ergonômico (PINHO; RODRIGUES; GOMES, 2007).

A insuficiência dos modelos preventivos em Saúde do Trabalhador é oriunda da dificuldade de hierarquização dos diversos fatores de risco reconhecidos e associados ao adoecimento das coletividades trabalhadoras. $\mathrm{O}$ que caracteriza a multicausalidade dos fatores de risco são as diversas causas ocorridas pela convergência de várias situações que participam simultaneamente, desencadeando os acidentes de trabalho (ECHTERNACHT, 2008).

$O$ trabalho de enfermagem voltado para a assistência à criança hospitalizada é desenvolvido em circunstâncias altamente estressantes. Uma situação que comumente ocasiona estresse e sobrecarga de 
trabalho é a participação da mãe/acompanhante durante este período de hospitalização, momento este marcado por grande desgaste físico, angústia, nervosismo e ansiedade, podendo gerar conflitos (COLLET; OLIVEIRA; VIEIRA, 2003).

Em busca de elementos de resposta às questões levantadas, foi estabelecido foco na atividade de trabalho do auxiliar e técnico de enfermagem de uma instituição hospitalar pediátrica, numa tentativa de se estabelecerem transformações, minimizando riscos de acidentes de trabalho.

\section{Objetivos}

Levantar os constrangimentos enfrentados pelos auxiliares e técnicos de enfermagem em sua atividade de trabalho e identificar estratégias utilizadas pelos trabalhadores que garantam as metas de produção, a satisfação do trabalhador e a sua autoproteção contra os acidentes de trabalho.

\section{Metodologia}

A amostra foi composta por 34 trabalhadores AeTE, entre efetivos e contratados, em um hospital público pediátrico. Foram entrevistados nos turnos correspondentes ao horário de trabalho.

A abordagem metodológica utilizada nesse trabalho teve como base a Análise Ergonômica do Trabalho (AET), método de ação da Ergonomia, definida como a descrição das atividades de trabalho, a partir de três etapas (GUERÍN, 2001).

A primeira etapa constou da observação da atividade dos AeTE do setor de urgência e emergência de uma instituição hospitalar pediátrica. Essa observação foi realizada em dias e plantões escolhidos pelos pesquisadores, aleatoriamente, com o objetivo de alcançar o maior número possível de profissionais. Nessa etapa, ocorreu a aproximação dos pesquisadores com os trabalhadores, o que facilitou a coleta de dados.

A segunda etapa consistiu em uma entrevista semiestruturada, autoaplicada, realizada com a população trabalhadora em foco, durante o seu período de trabalho, sem inviabilizar a atividade do profissional. Essa entrevista originou-se da adaptação de uma entrevista pré-existente utilizada em outras instituições que fazem parte de um projeto maior previamente aprovado pelo Comitê de Ética.

Essa descrição é validada a partir de uma terceira etapa fundamental da metodologia que é a entrevista em autoconfrontação (ACF) (GUERÍN, 2001), em que os pesquisadores realizaram questionamentos aos trabalhadores no momento da execução da atividade de trabalho, o que possibilitou a não racionalização das respostas fornecidas. Por meio das entrevistas, buscaram-se as imagens e representações utilizadas pelos participantes para expressar as vivências do trabalho na atividade de enfermagem (MENDES, 2006).

\section{Resultados}

\subsection{Hospital foco}

A instituição pediátrica em foco é uma unidade hospitalar de uma fundação estatal, maior rede de hospitais públicos da América Latina. Esta Fundação possui 23 unidades - nove situadas no interior, treze unidades hospitalares na capital e uma unidade de transplantes - que assistem à população de Minas e outros estados, oferecendo serviços especializados, em consonância com a política estadual de saúde.

Esta instituição possui como perfil assistencial assistir com qualidade às crianças referenciadas pelas macrorregiões do Estado de Minas Gerais e dos municípios que compõem a microrregião e a Região Metropolitana de Belo Horizonte, como centro de referência em atendimento ambulatorial, de internação e programas especiais do Governo em relação à pediatria, instituindo-se ainda como um hospital de ensino.

\subsection{Os elementos: auxiliares e técnicos de enfermagem}

Segundo a instituição, as principais atribuições específicas aos AeTE são:

- Executar cuidados integrais aos pacientes, sob supervisão do enfermeiro, integrando as equipes assistências multiprofissionais, buscando transdisciplinariedade e o cumprimento dos protocolos técnicos das ações;

- Executar tratamentos prescritos nas unidades assistenciais sob supervisão do enfermeiro, obedecendo a normas institucionais e de biossegurança e os protocolos assistenciais; e

- Desenvolver e executar ações de promoção da saúde do trabalhador e prevenção de acidentes de trabalho.

\subsection{Processo de Trabalho: o objeto e o meio de trabalho na enfermagem}

No processo de trabalho, nota-se que a natureza do objeto - paciente pediátrico - é caracterizada por recém-nascidos até crianças de 12 anos, de ambos os sexos, que apresentam principalmente patologias respiratórias, cardíacas e clínica geral.

A admissão do paciente inicia-se na "Classificação de Risco", em que ele é abordado por AeTE e submetido à verificação dos dados vitais, peso e altura. Depois desse momento passa por triagem, sendo seu estado classificado de acordo com a gravidade apresentada. Em seguida, recebe atendimento médico em que são prescritos os procedimentos de diagnóstico e tratamento, determinando o trajeto que o paciente desenvolverá 
dentro do hospital, que pode ser: orientações e alta, transferência, medicação, micronebulização, pequenos procedimentos, semi-internação ou internação (Figura 1).

A população alvo desse estudo caracteriza-se por AeTE do setor de Urgência e Emergência de um hospital pediátrico situado em Belo Horizonte - MG. Esse setor conta com um total de 59 profissionais, sendo estes classificados de acordo com o vínculo empregatício, efetivos/contratados, e gênero, masculino/feminino (Tabelas 1 e 2).

Dos 59 profissionais, 34 aceitaram participar da pesquisa em suas três etapas propostas da AET (Tabelas 3 e 4).

Os vínculos trabalhistas que a instituição mantém com os profissionais são de dois tipos: contratados e efetivos. Os contratados realizam um turno de trabalho de 12 horas, com folga de 36 horas, em período pré-determinado de 24 meses. Já os efetivos realizam um turno de trabalho de 12 horas com folga de 60 horas. Todos os auxiliares de enfermagem são efetivos, enquanto que todos os técnicos são contratados.

A supervisão de enfermagem não ocorre à distância, o que pode facilitar o compartilhamento dos saberes, experiências, o que pode diminuir principalmente a carga cognitiva.

Os rodízios de profissionais AeTE são constantes entre as áreas da Urgência e Emergência do hospital. Ocorrem a cada plantão em que todos estes profissionais são escalados, desde que não apresentem restrição médica. Caso isto ocorra, o profissional permanecerá em uma área em que sua condição clínica seja preservada. Em casos de falta de profissional, realiza-se um remanejo na escala, evitando que o trabalho seja prejudicado.

A Urgência e Emergência são subdivididas em áreas de classificação de risco, micronebulização, pequenos procedimentos, medicação e semi-internação. Estas áreas contam com um total de treze AeTE por plantão, sendo dois na classificação de risco, dois na micronebulização, dois nos pequenos procedimentos, um na medicação e seis na semi-internação (três enfermarias e dois AeTE em cada uma delas). Esse setor é constituído por um total de 27 leitos, sendo estes 26 na semi-internação e um nos pequenos procedimentos.

A alocação de pacientes nas enfermarias da semi-internação ocorre de maneira aleatória, não havendo critérios para a escolha de leitos, em que ele permanecerá em observação por um período máximo de três dias, podendo ser encaminhado para a internação ou receber alta hospitalar.

Segundo dados fornecidos pela Instituição, no período de março a julho, verificam-se um aumento do número de atendimentos médicos devido a mudanças climáticas. No mês de março de 2010 foram realizados 2.945 atendimentos médicos, o que necessariamente está associado ao aumento do trabalho dos AeTE.

\section{Discussão}

Os hospitais diferem de outras instituições pela marcante complexidade e peculiaridade dos serviços prestados (CARAPINHEIRO, 1998; ECHTERNACHT, 2000; MENDES et al., 2008), além de ser composto por uma variedade de profissionais. Utilizam tecnologias bastante diversificadas e sofisticadas, como equipamentos de diagnóstico de imagem, sistemas computadorizados e diferentes tipos de ferramentas e de medicamentos usados para o tratamento de doenças. A incorporação de novas tecnologias não significa, nesse setor, o "alívio da labuta humana",

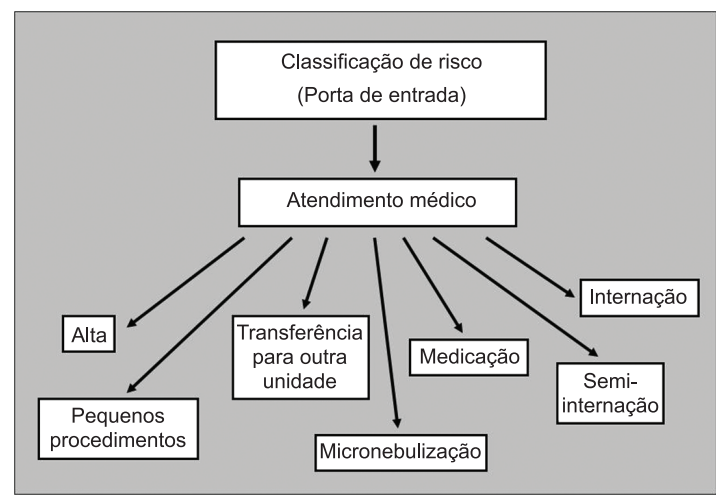

Figura 1. Fluxo produtivo da Instituição.

Tabela 1. Profissionais AeTE do setor de Urgência e Emergência: vínculo empregatício.

\begin{tabular}{lcc}
\hline $\begin{array}{c}\text { Vínculos } \\
\text { empregatícios }\end{array}$ & $\begin{array}{c}\text { Total de } \\
\text { profissionais }\end{array}$ & $\begin{array}{c}\text { Média de idade } \\
\text { (anos) }\end{array}$ \\
\hline Efetivos & 23 & 48,2 \\
Contratados & 36 & 36,8 \\
Total & 59 & - \\
\hline
\end{tabular}

Tabela 2. Profissionais AeTE do setor de Urgência e Emergência: gênero.

\begin{tabular}{ccc}
\hline Profissionais & Masculino & Feminino \\
\hline Total & 6 & 53 \\
\hline
\end{tabular}

Tabela 3. Profissionais AeTE do setor de Urgência e Emergência entrevistados: vínculos empregatícios.

\begin{tabular}{lcc}
\hline $\begin{array}{c}\text { Profissionais } \\
\text { entrevistados }\end{array}$ & $\begin{array}{c}\text { Total de } \\
\text { profissionais }\end{array}$ & $\begin{array}{c}\text { Média de idade } \\
\text { (anos) }\end{array}$ \\
\hline Efetivos & 5 & 36,4 \\
Contratados & 29 & 33,7 \\
Total & 34 & - \\
\hline
\end{tabular}

Tabela 4. Profissionais AeTE do setor de Urgência e Emergência entrevistados: gênero.

\begin{tabular}{ccc}
\hline $\begin{array}{c}\text { Profissionais } \\
\text { entrevistados }\end{array}$ & Masculino & Feminino \\
\hline Total & 6 & 28 \\
\hline
\end{tabular}


ao contrário, o setor é, essencialmente, de trabalho intensivo (MENDES et al., 2008).

Apesar da crescente importância que a tecnologia tem alcançando nos últimos tempos, o ponto forte do hospital é a interface pessoa-pessoa. O relacionamento entre seres humanos é o que dá dinamicidade a todo o sistema, transformando-o em algo extremamente complexo, que o diferencia de outros contextos. As relações multidisciplinares acontecem tanto de forma destrutiva como construtiva (MENDES, 2006).

Poucos locais de trabalho apresentam a complexidade do ambiente hospitalar, já que ele engloba a necessidade de interfaceamento de uma considerável quantidade de diferentes profissionais. Dentro daquele ambiente convivem grupos socioprofissionais muito particulares, uns ligados diretamente ao processo de prestação de cuidados à saúde humana e outros com a função de apoio ou de gestão (MENDES, 2006). As interfaces enfrentadas pelos AeTE dessa instituição são entre médicos, enfermeiros, pacientes, familiares e serviços gerais.

Segundo Carapinheiro (1998), a inserção dessa variedade de profissionais no ambiente hospitalar está organizada por uma forte hierarquização interna. O hospital apresenta uma organização burocrática em consequência de significativas mudanças na estrutura hierárquica devido ao crescimento de pessoal, multiplicação dos serviços e das especialidades médicas, bem como o aprimoramento tecnológico. Estas modificações provocaram importantes mudanças na estrutura hierárquica, na estrutura de poder e nos sistemas de comunicação do hospital, influenciando a expansão do sistema burocrático de administração profissional. A missão hospitalar é muito particular, pois trata de questões ligadas à vida e à morte, nas quais os profissionais possuem estratégias de trabalho próprias, porém com graus de autonomia bastante diferenciados. O conceito de autonomia está associado ao fato de que um indivíduo dispõe de autonomia quando pode controlar seu próprio trabalho assim como a forma de como e quando executá-lo (MENDES et al., 2008).

Uma análise mais detalhada da organização cotidiana do hospital mostra que nela emerge uma segunda autoridade, na qual alguns ocupam uma posição privilegiada na gestão das decisões, conferindo a algumas classes de profissionais um sistema de poder e de autoridade bem diferente de outras organizações, como, por exemplo, o caso do médico, que decide sempre o que é melhor para o paciente, ou seja, mesmo sendo um empregado do hospital, é ele que tem o controle efetivo das atividades fins da organização e não as autoridades administrativas (ECHTERNACHT, 2000). Nesse contexto, a autoridade não é regida pelas regras, mas sim por conhecimentos técnicos específicos
(CARAPINHEIRO, 1998; ECHTERNACHT, 2000; MENDES et al., 2008).

A subordinação do AeTE ao médico é fonte de conflito nessa relação, pois há uma restrição no campo de atuação. Os papéis do médico e do AeTE são delineados pela estrutura hierarquizada que indica limites, os quais são determinados pelas relações de poder e autoridade existentes na organização. Como verbalizado por um AeTE: "Tem colegas que engolem tudo que o médico manda e é isso que adoece a gente". Depois dessa narração, podemos verificar que os AeTE sentem-se desestimulados e sem autonomia para agir.

Questionamentos são levantados pelos AeTE quando determinadas tarefas realizadas são atribuições do serviço de enfermagem: "Essas enfermeiras querem que a gente faça o trabalho delas, já não basta o quanto a gente trabalha?! Acho que elas tinham que ter outro nome, porque enfermeira é quem cuida e não é o que elas fazem".

O poder de tomada de decisão desses trabalhadores é restrito, dependem da supervisão de enfermagem e de outros setores e suas possibilidades de ação obedecem às regras de funcionamento da instituição. Os rodízios entre os AeTE ocorrem constantemente, como verbalizado: "Sou igualzinho bola, me jogam para um lado e para o outro. Não gosto de rodar, prefiro ficar em um lugar só". Observa-se também que a realização do rodízio é mais frequente em AeTE contratados.

Observa-se um estranhamento frente ao trabalho, em que o trabalhador não se reconhece nesta atividade. Há uma expropriação do trabalho com o intuito de reproduzir os interesses do capital.

Pouco se sabe sobre o sentimento do trabalhador frente ao trabalho em si, suas relações com colegas, chefias, vínculos empregatícios e benefícios. Certamente, a compatibilização destas expectativas com as necessidades organizacionais, torna-se um desafio diante de obstáculos que se apresentam como longas jornadas de trabalho, condições inadequadas do ambiente; baixa remuneração; dupla jornada de trabalho e tensão emocional. As demandas de regulação, tanto individuais quanto coletivas, são necessárias para a escolha de ações mais adequadas à redução dos constrangimentos inerentes às situações encontradas durante a jornada de trabalho.

Diante de tantos elementos, que associados potencializam a cada momento situações novas de risco, emerge outro item que contribui para aumentar ainda mais a complexidade do ambiente hospitalar: o fator tempo. A dimensão temporal é um elemento forte e de maior importância no contexto hospitalar, estando associada às urgências e emergências decorrentes da imprevisibilidade dos eventos (ECHTERNACHT, 2002). 
Analisando as situações de trabalho, torna-se possível reconhecer na atividade a distância entre as prescrições das tarefas a serem realizadas e o trabalho real, e isso permite identificar os determinantes que condicionam a sua interação com o meio.

Os profissionais de enfermagem estão susceptíveis às pressões do trabalho, como a aceleração do processo de produção pela intensificação da demanda e da precariedade de recursos humanos e materiais. Ainda, somam-se a essas características as relações conflitantes que se originam da tensão instalada entre aqueles que experimentam a sobrecarga de trabalho (MENDES et al., 2008).

Os fatores que contextualizam a situação de trabalho do pessoal de enfermagem em vários países são as condições de trabalho oferecidas, as peculiaridades das tarefas de enfermagem, as dificuldades do setor saúde, a carência de recursos humanos e materiais e a constante preocupação com o processo de atualização, objetivando acompanhar os avanços técnico-científicos (ALVES; GODOY; SANTANA, 2006; ANDRADE, 2007).

Um dos pontos críticos que merece ser ressaltado é a falta de equipamentos que facilitariam não só o manuseio de materiais como também a manipulação de pacientes, segundo relato: "aqui falta equipamentos $e$ isso é uma dificuldade". A falta de manutenção de equipamentos e a utilização de mobiliários improvisados e inadequados também tornam o trabalho mais árduo para a equipe de enfermagem.

Os AeTE se queixam da falta de estrutura oferecida pela Instituição: "O pessoal não preocupa com esse hospital, a menina dos olhos de ouro da Instituição é o Hospital ' $X$ '”.

A objetivação do saber do cuidado de enfermagem é resultante de um processo coletivo em que os profissionais utilizam um corpo de conhecimento exteriorizado em técnicas que possam intervir no processo saúde-doença dos indivíduos, grupos, famílias e comunidades (FERNANDES et al., 2002; MARZIALE; RODRIGUES, 2002).

O saber é caracterizado pelo conhecimento dos AeTE a respeito de seu cotidiano de trabalho. Muitas vezes, conhecido por um saber-fazer, com pouco conhecimento técnico-científico.

$\mathrm{Na}$ exposição às cargas de trabalho, os AeTE comentam sobre o esforço físico exigido, período que permanecem em pé durante a jornada de trabalho, a manipulação de peso e a distância percorrida na instituição: "Não tem uma pessoa aqui que não tem dor, é na perna, na coluna".

Os AeTE também se queixam do ritmo de trabalho imposto, que os leva a ficarem longos períodos em pé, durante a execução de tarefas, devido ao número insuficiente de trabalhadores: "São dois e eram para ser quatro, a escala vive desfalcada".
Outro ponto relevante é a participação da mãe/ acompanhante durante a hospitalização o que contribui muito para o restabelecimento mais precoce da criança, bem como da melhor interação entre ela e sua família, diminuindo o estresse causado pela hospitalização. Contudo, a inserção da família, mãe/acompanhante, no período de hospitalização gera mudanças no processo de trabalho dos AeTE na unidade pediátrica, uma vez que passam a lidar diretamente com esses indivíduos (COLLET; OLIVEIRA; VIEIRA, 2003).

Esta situação gerou conflitos entre os membros da equipe, pois estes estavam acostumados a lidar com as crianças sem interrupções ou questionamentos sobre o que estava sendo realizado.

Percebemos na fala dos entrevistados que a presença do acompanhante traz modificações na sua rotina de trabalho: "os acompanhantes ajudam, mas, às vezes, atrapalham também. As mães querem saber de tudo, querem atenção o tempo todo. Haja paciência!".

Apesar dos desgastes ocasionados pelos trabalhos realizados, alguns trabalhadores vivenciam sentimentos como: alegria, satisfação, contribuição frente à sociedade, entre outros (Figura 2).

Os profissionais relatam que a questão dos vínculos empregatícios geram conflitos. Segundo os AeTE contratados, o contrato é um vínculo frágil, que não garante a motivação no trabalho: "O contratado sai daqui com uma mão na frente e a outra atrás. Só estamos aqui porque realmente precisamos. Fico procurando outra coisa lá fora porque sei que em dois anos estou na rua".

Tantos os contratados como os efetivos relatam o quanto é intensa a carga de trabalho a que são submetidos. Revelam as estratégias singulares e coletivas para gerir essa carga: “... a gente troca entre si, quando o serviço tá pesado todo mundo faz tudo".

A dupla jornada de trabalho é atribuída, principalmente, aos baixos salários, à sobrecarga e

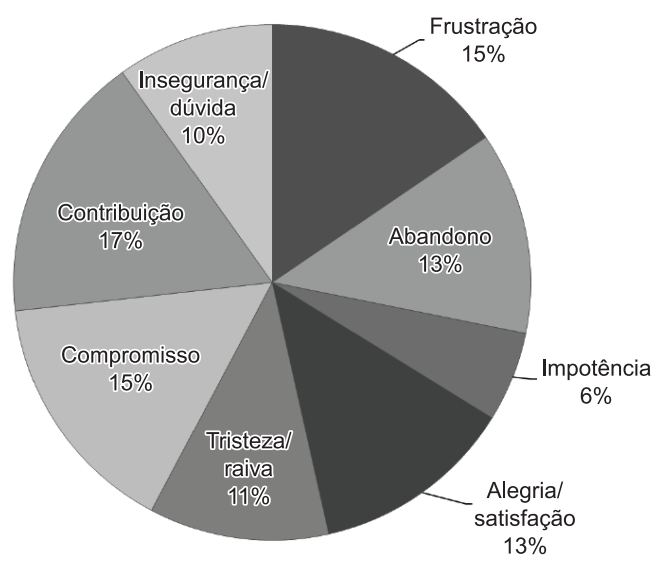

Figura 2. Sensações dos AeTE frente à profissão. 
à escassez de recursos humanos. Essa é uma realidade ainda frequente nos dias atuais e que resulta em maior esforço físico e mental desses profissionais, comprometendo, consequentemente, sua qualidade de vida. Por esse motivo, verifica-se a necessidade de que esses trabalhadores tenham dois ou mais vínculos empregatícios, como verbalizado: "Quando chego para trabalhar já tô cansada porque técnico de enfermagem nunca trabalha em um lugar só". Em consequência, sua atenção ao trabalho diminui e os submete a fortes pressões físico-emocionais, relacionando-se instavelmente com a equipe e são, por vezes, ansiosos ao atender pacientes.

A partir de tais constatações, cabe ressaltar que todos estes constrangimentos enfrentados pelos AeTE conduzem a um estado indicativo de transtorno. $\mathrm{O}$ trabalho deve ter como finalidade o desenvolvimento das potencialidades humanas. O profissional não deve ser vítima do seu trabalho e, sim, um instrumento essencial para tal tarefa, dotado de sentimentos, valores e qualidades fundamentais para o desempenho pleno do seu papel.

\section{Conclusão}

Pode-se concluir que, entre os constrangimentos levantados nesta Instituição, os mais evidentes são: a dupla jornada de trabalho, a diversidade de vínculos empregatícios, os riscos a que estes profissionais estão expostos e o não conhecimento do objeto de trabalho. Verifica-se que esses constrangimentos ocasionam a elevação das cargas de trabalho física, psíquica e cognitiva.

Existe uma grande distância entre a atividade imposta e a realizada pelo trabalhador. Para que as atribuições específicas dos AeTE sejam executadas com êxito, tornam-se necessárias as estratégias de regulações que são adquiridas por meio da vivência com o trabalho, das experiências e valores, contribuindo assim para a construção do projeto herança. Na inexistência desse projeto, o trabalhador se apropria da competência do outro para desenvolver sua regulação. As relações que se estabelecem entre a população de enfermagem e as interfaces com que lidam traduzem as estratégias utilizadas e as formas singulares dos usos de si.

Por fim, de acordo com os saberes, pode-se observar que, na atividade real de trabalho, a população trabalhadora cria a horizontalidade e, assim, ameniza o efeito das cargas de trabalho sobre sua condição trabalhadora e reduz os riscos de acidente de trabalho. Dessa forma, conclui-se que o adoecimento da população de enfermagem, AeTE, ocorre em virtude da não construção dessa horizontalidade (parcerias de trabalho), diminuindo a possibilidade de regulação em uma população novata e mais jovem.

\section{Referências}

ALEXANDRE, N. M. C. Aspectos ergonômicos relacionados com o ambiente e equipamentos hospitalares. Revista Latino-Americana de Enfermagem, v. 6, n. 4, p. 103-109, 1998. http://dx.doi.org/10.1590/ S0104-11691998000400013

ALVES, M.; GODOY, S. C. B.; SANTANA, D. M. Motivos de licenças médicas em um hospital de urgênciaemergência. Revista Brasileira de Enfermagem, v. 59, n. 2, p. 195-200, 2006. PMid:17051890. http://dx.doi. org/10.1590/S0034-71672006000200014

ANDRADE, A. C. A enfermagem não é mais uma profissão submissa. Revista Brasileira de Enfermagem, v. 60, n. 16, p. 96-98, 2007. http://dx.doi.org/10.1590/ S0034-71672007000100018

CARAPINHEIRO, G. Saberes e poderes no hospital. 3. ed. Porto: Edições Afrontamento, 1998.

COLLET, N.; OLIVEIRA, B. R. G.; VIERA, C. S. Processo de trabalho em pediatria hospitalar. In: SEMINÁRIO NACIONAL: ESTADO E POLÍTICAS SOCIAIS NO BRASIL, 2003, Cascavel. Anais... Cascavel: EdUNIOESTE, 2003. v. 1, 15 p.

ECHTERNACHT, E. H. O.; OLIVEIRA, C. O Hospital e o Pessoal: Um estudo de caso sobre a produção de lesões por esforços repetitivos na lida com a organização temporal hospitalar. Ação Ergonômica, v. 1, n. 1, p. 79-90, 2000.

ECHTERNACHT, E. Sobre a carga de trabalho. Belo Horizonte: Escola de Engenharia da UFMG, 2002.

ECHTERNACHT, E. Atividade humana e gestão de saúde no trabalho: elementos para a reflexão a partir da abordagem ergológica. Laboreal, v. 4, n. 1, p. 46-55, 2008.

EGGERS, C.; GOEBEL, M. A. Princípios de higiene e segurança no trabalho. Toledo: UNIOESTE, 2005.

FERNANDES, J. D. et al. Saúde mental e trabalho feminino: imagens e representações de enfermeiras. Revista Latino-Americana de Enfermagem, v. 10, n. 2, p. 199-206, 2002. PMid:12138565. http://dx.doi. org/10.1590/S0104-11692002000200012

FERREIRA, M. C.; FREIRE, O. N. Carga de trabalho e rotatividade na função de frentista. Revista de Administração Contemporânea, v. 5, n. 2, p. 175-200, 2001.

GUERÍN, F. Compreender o trabalho para transformá-lo: a prática da ergonomia. São Paulo: USP, Fundação Vanzolini, Edgard Blücher, 2001. 200 p.

MARZIALE, M. H. P.; RODRIGUES, C. M. A produção científica sobre os acidentes de trabalho com material perfurocortante entre trabalhadores de enfermagem. Revista Latino-Americana de Enfermagem, v. 10, n. 4, p. 571-577, 2002. PMid:12592859. http://dx.doi. org/10.1590/S0104-11692002000400015

MENDES, D. P. Donos do Poder? Uma análise da atividade pericial no contexto da previdência social brasileira: limites e conflitos frente à caracterização do adoecimento em LER/DORT. 2006. Tese (Mestrado em Engenharia de Produção)-Universidade Federal de Minas Gerais, Belo Horizonte, 2006.

MENDES, D. et al. Um olhar sobre a atividade de trabalho de auxiliares e técnicos de enfermagem 
de uma instituição psiquiátrica: em busca de transformações. In: CONGRESSO BRASILEIRO DE ERGONOMIA, 15., 2008, Porto Seguro. Anais... Porto Seguro, 2008.

MENDES, D. P.; MORAES, G. F. S.; MENDES, J. C. L. Análise da gestão de risco no trabalho de enfermagem em uma instituição psiquiátrica. Trabalho \& Educação, v. 20, n. 1, p.73-84, 2011.

MENDES, R.; DIAS, E. C. Da medicina do trabalho à saúde do trabalhador. Revista de Saúde Pública, v. 25, n. 5, p. 341-349, 1991. PMid:1820622.

MENDES, R. Patologia do Trabalho. 2. ed. São Paulo: Atheneu, 2003. v. 1, 200 p.
PINHO, D. L. M.; RODRIGUES, C. M.; GOMES, G. P. Perfil dos acidentes de trabalho no Hospital Universitário de Brasília. Revista Brasileira de Enfermagem, v. 60, n. 3, p. 291-294, 2007. PMid:17684906. http://dx.doi. org/10.1590/S0034-71672007000300008

REIS, R. J. et al. Fatores relacionados ao absenteísmo por doença em profissionais de enfermagem. Revista de Saúde Pública, v. 37, n. 5, p. 616-623, 2003. http:// dx.doi.org/10.1590/S0034-89102003000500011

WÜNSCH FILHO, V. Reestruturação produtiva e acidentes de trabalho no Brasil: estrutura e tendências. Caderno de Saúde Pública, v. 15, n. 1, p. 41-51, 1999. PMid:10203445. 